\title{
ENSAYO-RESEÑA
}

\section{LA EXPLICACIÓN SOCIAL DE LOS TRASTORNOS ALIMENTARIOS: UNA LECCIÓN DE RIGOR FRENTE A LOS TRUCOS DEL ILUSIONISMO}

\author{
Francisco Vázquez García \\ Universidad de Cadiz
}

Moreno Pestaña, José Luis, Moral corporal, trastornos alimentarios y clase social, Madrid, Centro de Investigaciones Sociológicas, 2010, 321 págs. [ISBN 978-84-7476-487-1]

Comenta Nietzsche, en un aforismo incluido en Aurora, que la ciencia funciona al revés que la prestidigitación. En ésta, el mago nos hace ver - haciendo desparecer al sempiterno conejo- una causalidad simple donde en realidad opera la compleja causalidad del truco y del montaje. La ciencia en cambio (al explicar algo de aspecto tan corriente como la caída y la puesta de sol, por ejemplo) nos revela que tras la aparente simplicidad se oculta un mecanismo causal bastante complicado.

Este mismo empeño es el que gobierna la investigación de José Luis Moreno Pestaña. Se trata por una parte de un análisis sociológico de los trastornos alimentarios. En ningún caso se niega la condición patológica de éstos. Frente a versiones más o menos vulgares de Foucault o de la «teoría del etiquetaje», filtradas políticamente por el feminismo, la queer theory o la antipsiquiatría, se afirma decididamente que los trastornos alimentarios constituyen una enfermedad. No se está ante construcciones sociodiscursivas promovidas por un aparato psiquiátrico puesto al servicio de las fuerzas del patriarcado, el control social o la clase dominante.

Ahora bien, este reconocimiento de la condición patológica inducida por restricciones alimentarias intensas, implica al mismo tiempo recordar que no se trata sin más de patologías orgánicas o psíquicas, sino que hay dinámicas sociales que las propician. Aquí se toma distancia tanto de las explicaciones biologicistas como de las cognitivo-conductuales o psicoanalíticas.

Más allá de esas causalidades sencillas, «ídolos del teatro» que funcionan como «refugios de la ignorancia» (Spinoza dixit), trátese de fuerzas sociales abstractas (Patriarcado, Poder psiquiátrico, Capitalismo, Sociedad reflexiva, etc..) o de entidades biológicas o psíquicas invocadas al modo de «virtudes dormitivas» (genes, neurotransmisores, hormonas, traumas), o simplemente del azar y la contingencia individuales, se trata de explorar esas dinámicas sociales propiciatorias, siguiéndolas en toda su complejidad y concreción, no remitiendo a causas sin más, sino desgranando en detalle y 
en toda su variedad de registros, los mecanismos sociales implicados. Esta voluntad de rigor envuelve toda la argumentación y contrasta a la vez con el ilusionismo de las explicaciones postmodernas y objetivistas, y con el funambulismo de los que invocan una mezcla difusa de lo social y lo biopsíquico para dar cuenta de estos trastornos.

Pero además de un análisis sociológico ejemplar y pionero, el trabajo revela, al hilo de la ingente cantidad y diversidad de materiales empíricos contrastados, una serie de aportaciones filosóficas de primer orden. Así sucede en relación con problemas epistemológicos (¿en qué se distingue el conocimiento práctico y «fronético» del terapeuta respecto al puro conocimiento teórico?; ¿cómo se pueden transformar los enunciados performativos acerca de la enfermedad mental en enunciados constatativos?); antropológicos (¿qué concepto del ser humano está involucrado en una teoría disposicional de la acción?); ontológicos (¿qué perfiles puede tener una entidad como la enfermedad mental?) y éticos (¿qué capacidad de acción, qué grado de libertad tienen aquellos que no pueden apaciguar su tensión corporal y caen bajo la gestión terapéutica?; ¿qué recursos y estrategias despliegan para salir de la situación a la que han llegado?). La discusión filosófica se desliza siempre al hilo de la resolución de problemas empíricos; no se trata de comentarios al margen ni de digresiones extemporáneas. Un ejemplo magistral de este ejercicio lo representa un pasaje del capítulo 4 (pp. 144-148), cuando intentando dar cuenta del habitus de un grupo de amas de casa de extracción popular, ambivalentes ante las restricciones alimentarias, introduce la teoría spinozista del «individuo compuesto» para explicar la variable composición disposicional del individuo y de las posibilidades de cambiarla.

En vez de considerar los trastornos alimentarios como una categoría nosográfica fija y bien delimitada, objetivable en datos como el índice de masa corporal o en conductas como el vómito intencionado o las restricciones dietéticas extremas, se opta por tematizarlos a partir de la noción de «carrera corporal tensa». Se trata de una trayectoria o escalera de subida donde la tensión corporal puede acabar derivando en la administración de la propia vida por la terapia profesional, pero que admite asimismo el camino inverso, deteniendo los actos que propician las disposiciones restrictivas hasta llegar a deshacerlas y reconfigurar el conjunto del habitus. En cualquier caso, esta carrera no se produce nunca en un vacío social; los «datos objetivos» como el índice de masa corporal o las conductas sintomáticas no son sino el eventual resultado visible de una trayectoria que remite siempre a un contexto. En éste se entrecruzan, siempre en la estela de la dimensión temporal de la experiencia, las normas somáticas del grupo familiar, del grupo de pares, del medio laboral y de la lógica de los mercados sexual y matrimonial. Aquí comparece también el medio terapéutico, entendido como un campo plural de fuerzas y no como un «aparato» o bloque monolítico (aunque el grado de pluralidad pueda variar según el contexto y la trayectoria considerada), atravesado no sólo por profesionales de distinta índole y por opciones explicativas y terapéuticas diversas, sino también por las interacciones que mantienen con ellos los propios afectados y las asociaciones de familiares.

La noción de «carrera corporal tensa» obliga a cuestionar el uso - habitual en el medio de los profesionales clínicos pero también en ámbitos profanos- de ciertas dicotomías conceptuales rígidas. Por una parte se hace insostenible la distinción tajante y sustantiva entre lo normal y lo patológico; no existe una frontera clara que permita decidir en cualquier caso y de modo descontextualizado, en qué momento la tensión corporal ingresa en el espacio de la enfermedad. En segundo lugar, la noción de «carrera» impugna divisiones taxonómicas consagradas, como la que separa a la anoréxica de la bulímica, como si se tratase de casos clínicos perfectamente diferenciables. Pero Moreno Pestaña no se limita a impugnar; revela el inconsciente de clase que subyace a semejante distinción nosográfica y que se filtra tanto en el discurso profano como en el de los especialistas.

Por último, el concepto de «carrera» lleva a poner en tela de juicio la propensión del análisis sociológico a considerar las distintas variables causales como si actuaran simultáneamente. Este enfoque, muy común en el empleo, por ejemplo, del análisis multivariado, debe reemplazarse por una consideración atenta a la acción de causalidades en el eje temporal, lo que lleva a preferir técnicas cualitativas como la historia de vida. 


\section{ENSAYO-RESEÑA}

El comienzo de una carrera corporal tensa se produce al participar en interacciones sociales donde la posesión de un capital corporal elevado desempeña un papel primordial. Piénsese por ejemplo en las exigencias del mercado sexual para los grupos de pares juveniles en medio urbano y que aún no han ingresado en la vida de pareja estable. Moreno Pestaña codifica las interacciones en estos mercados tensos a partir de la teoría de los rituales de interacción desarrollada por Randall Collins.

Los trastornos alimentarios implican que la interacción en estos mercados corporales tensos, ocupa el centro de atención de la persona, hasta el punto de relegar completamente los demás universos de interacción social. A partir de aquí, y apoyándose en las aportaciones de Merleau-Ponty, se elabora una ontología alternativa de la enfermedad mental a propósito de los trastornos de la alimentación. La enfermedad consiste en una pérdida de los campos sensoriales compartidos que estructuran nuestra experiencia. Las personas se concentran exclusivamente en el control de una parte de esa experiencia (las interacciones corporales en este caso) a costa de perder el control de ámbitos importantes que permiten la convivencia con los otros (los familiares, compañeros de trabajo, amistades, parejas, etc..). En esta idea de la enfermedad como una suerte de «escolástica permanente», de encierro en una única posibilidad vital, se hace patente también la conceptualización de lo patológico elaborada por Georges Canguilhem. La enfermedad consiste, según este autor, no en la inadaptación al entorno, sino en la imposibilidad de alterar las normas vitales, de crear nuevas normas ante el cambio operado en el entorno.

Como se ha podido evidenciar, las fuentes teóricas del estudio son extraordinariamente ricas y variadas. Prima sin duda la referencia a una tradición de pensamiento social de raíz fenomenológica que pasa por Merleau-Ponty, Canguilhem, Bourdieu, Passeron, Grignon o Foucault y que guarda claras afinidades con la microsociología de Goffman, Becker y Randall Collins. Pero en el trasfondo de esta tradición se localiza una teoría disposicional de la acción, de filiación aristotélica, que además de remitir al Estagirita atraviesa referencias tan diversas como las de Tomás de Aquino, Spinoza, Austin, Searle, Hacking o Althusser. Ya desde la presentación que abre el libro, y esto reaparece en distintos momentos del mismo, la investigación se presenta como un camino en el que el propio autor ha tenido que desaprender y alterar ciertas disposiciones intelectuales (e intelectualistas) interiorizadas en una atmósfera teórica dominada por cierto postmodernismo en ciencias sociales. Es como si, de forma análoga a como sucede en algunas de las carreras corporales tensas evocadas en el estudio, Moreno Pestaña hubiera tenido que desandar una carrera teórica tensa, haciendo el duelo y la renuncia - o el reajuste, como le sucede con Foucault, invocado a la vez como «obstáculo y ayuda» para su trabajo - de las alternativas teóricas inicialmente adquiridas.

Como buen fenomenólogo, Moreno Pestaña nunca pierde de vista la atención «a las cosas mismas», al problema planteado a través de la enorme cantidad de información contrastada en su trabajo. Las aportaciones teóricas son sólo herramientas para dar forma y sentido a las dificultades empíricas encontradas, no constituyen un fin en sí mismas, de ahí ese sano y coherente eclecticismo conceptual que recorre toda la investigación. La información empírica, obtenida principalmente a través del trabajo etnográfico desarrollado durante más de dos años en una asociación de familiares de afectados, es organizada en una trama de configuraciones comparables mediante el recurso a procedimientos cualitativos: la entrevista y la historia de vida para el análisis de las «carreras»; el grupo de discusión para captar la diversidad de culturas somáticas según las distintas fracciones de clase; el uso reiterado del «espacio de atributos» - instrumento elaborado por Paul Lazarsfeldpara ordenar el espacio de posibles lógicos y contrastarlo con las combinaciones empíricamente existentes. A estos procedimientos hay que añadir la frecuente utilización de cuadros comparativos, de fragmentos textuales obtenidos a través de la observación etnográfica, de fuentes literarias e incluso de datos estadísticos, como los referidos a la relación entre sobrepeso, autopercepción y clase social, elaborados a partir de las tablas publicadas por la Encuesta Nacional de Salud.

Con estos mimbres se elabora un texto secuenciado en ocho capítulos que acompañan a una presentación y a un apartado de conclusiones. El primer capítulo es un ejercicio de reflexividad que 
contextualiza en la propia trayectoria el punto de partida de la investigación, toma distancia respecto a otros enfoques del problema y refiere las dificultades encontradas en el proceso de análisis. El segundo capítulo está centrado en la formulación de un modelo ontológico de enfermedad mental, inspirado en Merleau-Ponty y alternativo tanto respecto a las visiones objetivistas como frente a la denegación postmoderna. El tercer capítulo sitúa en sus justos límites la validez de un modelo ampliamente extendido entre antropólogos y sociólogos de la enfermedad mental. Se trata de la representación de ésta como el resultado de la colonización psiquiátrica de la vida cotidiana. Así por ejemplo, la anorexia no sería más que un invento de la psiquiatría alentado por la voluntad de control social y el encauzamiento disciplinario de las conductas. Los afectados - empezando por los pacientes burgueses - interiorizarían la etiqueta fabricada y, al modo de una profecía autorrealizada, acabarían amoldando su experiencia a lo que el conocimiento experto espera de ellos. Este argumento, que según el autor, puede servir para dar cuenta de ciertos procesos observados en la investigación (por ejemplo la asunción del discurso más biologicista e inflacionista de la anorexia en el ámbito de las asociaciones de familiares), se convierte en una caricatura que puede impugnarse tanto en el plano conceptual - aquí es crucial el recurso al análisis del construccionismo realizado por Hacking - como en el empírico. En este caso la prueba viene dada por la existencia de personas enfermas, es decir, con trastornos alimentarios, sin que en ellas mediara la presencia de diagnóstico psiquiátrico alguno. El análisis fenomenológico de la experiencia vivida de estas personas, en clave de correlación entre nóesis y noema, le permite a Moreno Pestaña captar esta alteración de los campos sensoriales compartidos, antes de todo etiquetaje experto.

El cuarto capítulo entra ya en la indagación de las condiciones sociales, diferenciadas según las clases y fracciones de clase - además de variables como el género y la clase de edad - que contextualizan la posibilidad de emprender carreras corporales tensas. Se trata en este caso de delimitar, mediante el trabajo con varios grupos de discusión, las distintas culturas somáticas propias de las clases populares. Se traza así un espectro que va desde los varones adultos del mundo campesino hasta las mujeres procedentes de fracciones situadas en el límite con las clases medias. Más allá de las disparidades entre estos diversos grupos, rotuladas con minuciosidad, se pone de relieve la existencia de una "economía moral» — además de unas restricciones de índole económica- que actúa como un mecanismo de resistencia frente a la tensión corporal y que se expresa, entre otras cosas, en una intensa estigmatización popular de la mujer anoréxica. Esta economía moral funcionará como fuente de recursos a la hora de desandar el camino de la carrera corporal tensa. El autor - esto se pone de relieve al final de las conclusiones - le otorga por ello una importancia especial, hasta el punto de aspirar, mediante la delimitación de sus mecanismos, a colaborar en la formación de una conciencia política en relación con aquéllos. En el quinto capítulo, el protagonismo se desplaza a los jóvenes procedentes de las clases populares. Se trata en principio de grupos más receptivos a los procesos de tensión corporal. No obstante, existen grandes diferencias. Para hacerlas inteligibles el autor explora la relación que se da entre los tipos ideales que corresponden a las distintas trayectorias encontradas y las diversas configuraciones familiares que actúan posibilitando o restringiendo esas trayectorias. Contrastan así las familias que permiten una fuerte individualización de los habitus corporales y aquellas en las que las fuerzas centrípetas restringen esta posibilidad. Se recorre con mucho detalle toda la paleta de estrategias posibles dentro de este universo, desde el acatamiento hasta la resistencia pasando por la «asimilación con eclipses», además de tener en cuenta los efectos de distensión producidos por el ingreso temprano en la vida matrimonial o en la pareja estable.

El sexto capítulo cambia el foco de atención. Se dirige ahora a la reconstrucción de las trayectorias en el marco de las culturas somáticas propiciadas en las fracciones de las clases medias y dominantes. Atendiendo a los recursos económicos, culturales, corporales y al recorrido ascendente o descendente en la movilidad social, se traza el espacio de combinaciones posibles. Se trata de un universo donde la tensión corporal intensa forma parte de las rutinas cotidianas. En el medio de las 


\section{ENSAYO-RESEÑA}

fracciones de clase alta aparece la distinción entre una belleza corporal ligada al éxito y a la restricción y el cuidado explícitos (donde el capital económico prima sobre el cultural) y una belleza vinculada al cuerpo maldito y subversivo (típico de las fracciones intelectuales y artísticas de la burguesía), donde la restricción y el cuidado explícitos aparecen denegados. En este espacio es donde se produce la mayor inflación discursiva, proliferando las explicaciones propias de la vulgata postmoderna (y del psicoanálisis), que realzan la figura de la anoréxica como resistencia a las normas de género o la presentan como un invento del poder psiquiátrico, al tiempo que se refuerza la distinción etnocéntrica entre anoréxicas y bulímicas.

En el capítulo séptimo y en parte del octavo, el centro de atención lo constituye el análisis sociológico del juicio clínico. Este apartado, asentado en la observación etnográfica continuada de un grupo de profesionales terapéuticos, efectúa un saludable barrido de tópicos. Se deshace la imagen foucaultiana de un dispositivo psiquiátrico monolítico, donde los afectados aparecen fagocitados por la colonización cultural de los expertos. En vez de semejante cuadro, lo que aparece es un campo muy fragmentado, tanto por la diversidad de profesionales concernidos como por la pluralidad de corrientes dentro de cada profesión. Además, el tête a tête no se produce sólo entre pacientes y expertos; concierne también a una lucha entre especialistas, con los afectados jugando bazas a favor de unos o de otros (como sucede en la alianza entre asociaciones de familiares y psiquiatras biologicistas). Por otro lado, los habitus de los terapeutas distan de ser de una pieza; la retórica más dogmática e intelectualista utilizada en los medios de comunicación contrasta con el discurso utilizado en el trabajo clínico diario, mucho más matizado y con un funcionamiento menos rígido en las taxonomías utilizadas. Finalmente, se evidencia la proyección de la experiencia vivida y de la trayectoria social de los propios profesionales en su misma tarea clínica; el ogro frío y administrador de etiquetas y de recetas terapéuticas disciplinarias deja su paso a una figura mucho más vulnerable y cercana.

Además de proseguir esta sociología de la mirada clínica, el capítulo octavo examina la peculiar relación que se da entre el afectado y el menú terapéutico a su disposición. Éste es tanto más variado cuanto más prolongada sea la carrera desviante, siempre que esta tenga lugar en un contexto de importantes recursos económicos y culturales. Se reconstruyen todas las combinaciones posibles, pero el autor se detiene especialmente en la que acabamos de mencionar, donde se despliegan procesos de «cronificación dulce»; la variedad de opciones terapéuticas consumidas le permite al usuario, procedente de las fracciones de clase alta, aferrarse a las que presentan una imagen más favorable de su afección, manteniendo a la vez las conductas propias de una carrera corporal tensa y el apaciguamiento ofrecido por la asistencia terapéutica profesional. Más allá de ésta, se pasa revista, en este mismo capítulo, a otras formas de salida o de marcha atrás en las etapas de la carrera desviante. Aquí se hace un uso fecundo del concepto foucaultiano de «tecnologías del yo». La reapropiación del propio cuerpo y el necesario olvido del mismo para poder convivir con los demás, puede apoyarse en estrategias diversas. Estas van desde la revalorización erótica del propio físico a través de la vida en pareja (incluido el redescubrimiento de los placeres gastronómicos) hasta el activismo crítico de signo feminista pasando por la confirmación afectiva del propio cuerpo procedente de los propios familiares. En estas salidas no terapéuticas se advierte el valioso recursos que significan los mecanismos morales de resistencia a la tensión corporal típicos de las familias de extracción popular.

Las conclusiones que cierran el libro retoman de un modo sistemático las principales interrogantes abiertas en él. Aquí se hace patente la importancia de las contribuciones, no sólo sociológicas sino también filosóficas, de un texto que está destinado a convertirse en obra de referencia en ambos terrenos. En el sociológico por abordar el problema dejando atrás los obstáculos inducidos por una mirada excesivamente dada a panorámicas «macro» que reducen la especificidad de las dinámicas sociales implicadas en los trastornos, a grandes relatos acerca del destino de la modernidad reflexiva, de la dominación patriarcal o del poder psiquiátrico. En este aspecto, el privilegio del 
microanálisis y de un cierto individualismo metodológico, representan una virtud. El libro no lo explica todo ni lo pretende. Menos mal. No entra en la historia del diagnóstico (en España) ni reconstruye las luchas, que entrelazan a distintos campos (intelectual, terapéutico, político, mediático) por apropiarse del espacio de los trastornos alimentarios, como tampoco entra a considerar las condiciones que pueden llevar al deterioro e incluso a la aniquilación de esos modos de resistencia a la tensión corporal evidenciados en las clases populares. Gracias a un ejemplar trabajo de delimitación de su objeto y de administración de la prueba, no sólo detecta las condiciones sociales de la enfermedad, sino que abre un sinfín de pistas que pueden ser explotadas para trabajar análogamente sobre otras enfermedades. Más que un libro, lo que se ofrece es todo un programa de investigaciones posibles. Por último, el trabajo es exponente de un nuevo y raro modo - al menos en las Universidades españolas - de ejercicio filosófico. Cuando en nuestras facultades de filosofía se habla de «ciencia social crítica», las referencias que se vienen a la cabeza suelen ser libros como la Dialéctica de la Ilustración o, entre los más avezados, obras como Vigilar y Castigar. Hacer ciencia social crítica, en estos contextos, suele consistir en combinar, de forma más o menos atinada, argumentos y conceptos tomados de libros de esta índole. La falta de competencias debidas a un mal diseño de las carreras universitarias — ya denunciado en su día por Manuel Sacristán- hace impensable que la ciencia social crítica de nuestros filósofos profesionales vaya más allá del comentario de textos, del combinado teórico de puras teorías. Nadie parece echar en falta el trabajo de materiales empíricos de primera mano y el conocimiento de las técnicas (entrevistas, historias de vida, grupos de discusión, análisis estadístico, construcción de espacios de atributos, crítica de fuentes de archivo, etc..) necesarias para ello. Moreno Pestaña muestra que otro modo de entender esta tarea es posible. 